BNL-73474-2005-CP

\title{
Simulation of Resonance Streaming at the eRHIC Electron Storage Ring
}

\author{
C. Montag \\ Presenfed at fhe Particle Accelerator Conference(PAC'05) \\ Knoxville, Tennessee \\ May 16-20,2005
}

Collider-AcceleratorDepartment

Brookhaven National Laboratory

P.O. Box 5000

Upton, NY 11973-5000

www.bnl.gov

Managed by

Brookhaven Science Associates, LLC

for the United States Department of Energy under

Contract No. DE-AC02-98CH10886

This is a preprint of a paper intended for publication in a journal or proceedings. Since changes may be made before publication, this preprint is made availablewith the understanding that it will not be cited or reproduced without the permission of the author. 


\section{DISCLAIMER}

This report was prepared as an account of work sponsored by an agency of the United States Government. Neither the United States Government nor any agency thereof, nor any of their employees, nor any of their contractors, subcontractors, or their employees, makes any warranty, express or implied, or assumes any legal liability or responsibility for the accuracy, completeness, or any third party's use or the results of such use of any information, apparatus, product, or process disclosed, or represents that its use would not infringe privately owned rights. Reference herein to any specific commercial product, process, or service by trade name, trademark, manufacturer, or otherwise, does not necessarily constitute or imply its endorsement, recommendation, or favoring by the United States Government or any agency thereof or its contractors or subcontractors. The views and opinions of authors expressed herein do not necessarily state or reflect those of the United States Government or any agency thereof.

FOR UNCLASSIFIED, UNLIMITED STI PRODUCTS

Available electronically at:

OSTI:

http://www.osti.gov/bridge

Available for a processing fee to U.S. Department of Energy and its contractors, in paper from:

U.S. Department of Energy

Office of Scientific and Technical Information

P.O. Box 62

Oak Ridge, TN 37831

Phone: (865) 576-8401

Facsimile: (865) 576-5728

E-mail: reports@adonis.osti.gov

National Technical Information Service (NTIS):

Available for sale to the public from:

U.S. Department of Commerce

National Technical Information Service

5285 Port Royal Road

Springfield, VA 22131

Phone: (800) 553-6847

Facsimile: (703) 605-6900

Online ordering: http://www.ntis.gov/ordering.htm

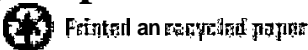




\title{
SIMULATION OF RESONANCE STREAMING AT THE ERHIC ELECTRON STORAGE RING *
}

\author{
Christoph Montag, Brookhaven National Laboratory, Upton, NY 11973, USA
}

\begin{abstract}
To estimate electron beam lifetime and detector background at the future electron-ion collider eRHIC, knowledge of the electron beam halo region is essential. Simulations have been performed to determine the deviation of the transverse beam profile from a Gaussian distibution.
\end{abstract}

\section{INTRODUCTION}

To study collisions between polarized electrons and relativistic heavy ions or polarized protons, adding a $10 \mathrm{GeV}$ electron storage ring to the existing RHIC accelerator complex is under consideration[1]. In this eRHIC facility, beam-beam tuneshift parameters of $\xi_{y}=0.08$ are required for the electron beam in order to achieve a luminosity of several $10^{32} \mathrm{~cm}^{-2} \mathrm{sec}^{-1}$. The resulting beam dynamics in the presence of the beam-beam interaction needs to be studied carefully. For that purpose the beam-beam problem can be divided into two different regimes, namely the core and the halo of the electron beam. While the behavior of the beam core determines the luminosity performance of the machine, the evolution of the tails determines the beam lifetime and detector background levels.

\section{SIMULATION RESULTS}

The simulation technique applied to the study of the transverse beam tails is similar to the one developed by Shatilov [2] and Chen, Irwin, and Siemann [3]. Using normalized coordinates and momenta,

$$
\begin{aligned}
x & =A_{x} \sigma_{x} \cos \left(\phi_{x}\right), \\
x^{\prime} & =A_{x} \sigma_{x^{\prime}} \sin \left(\phi_{x}\right), \\
\mathrm{Y} & =A_{y} \sigma_{y} \cos \left(\phi_{y}\right), \\
y^{\prime} & =A_{y} \sigma_{y^{\prime}} \sin \left(\phi_{y}\right), \\
\alpha_{x} & =\alpha_{y}=0,
\end{aligned}
$$

the amplitude plane (A, A,) is divided into cells with a size sufficiently small to ensure good resolution [2],

$$
\mathbf{A A}<2 \sqrt{\alpha}
$$

where the damping decrement $\alpha$ is defined as the inverse of the damping time. In the simulations describedhere, the cell size is chosen as $\mathbf{A A}=0.005$.

A single particle is tracked for ten thousand dampingtimes;

\footnotetext{
*Work performed under the auspices of the U.S.Department of Energy
}

\begin{tabular}{lr}
\hline \hline electrons: & \\
ring circumference[m] & 1278 \\
number of bunches & 120 \\
geometric emittancehor./vert. [nm] & $53 / 9.5$ \\
$\beta$ functionshor./vert. [m] & $0.19 / 0.27$ \\
bunch length [mm] & 11.7 \\
synchrotrontune & 0.04 \\
particles/bunch & $1.0 \cdot 10^{11}$ \\
beam-beam tune shifthor./vert. & $0.027 / 0.08$ \\
damping times hor./vert./long. [turns] & $1740 / 1740 / 870$ \\
\hline hadrons: & \\
ring circumference [m] & 3834 \\
number of bun ches & 360 \\
geometric emittancehor./vert. [nm] & $9.5 / 9.5$ \\
$\beta$ functionshor./vert. [m] & $1.08 / 0.27$ \\
particleshunch & $1.0 \cdot 10^{11}(\mathrm{p})$, \\
& $1.0 \cdot 109(\mathrm{Au})$ \\
beam-beam tune shifthor./vert. & $0.007 / 0.0035$ \\
\hline beam spot size hor.vert. [ $\mu \mathrm{m}$ ] & $100 / 50$ \\
luminosity [cm ${ }^{-2}$ sec $^{-1}$ ] & $4.4 \cdot 10^{32}$ \\
\hline
\end{tabular}

Table 1: Interaction region parameters of the electron-ion collider eRHIC.

the tracking includes the linear one-turn matix, the beambeam interaction, and radiation damping and quantum excitation. After each tum the betatron amplitudes $A,, A$, are calculated and the density of the corresponding cell in the $\left(A_{x}, \mathrm{~A}\right.$, ) plane is incrementedby one. After ten thousand damping times cells with a density above one tenth of the density at the center $\left(\mathrm{A}, A_{y}\right)=(1,1)$ are assigned as region $\mathbf{I}$, and cells with a lower density are assigned as region $I I$. During another ten thousand damping times of tracking, phase space coordinates of the particle are saved whenever it moves from region $\mathbf{I}$ to region $\mathbf{I I}$.

In the next step, region $\mathbf{I}$ becomes region $\boldsymbol{O}$, the hidden region, while region $\mathbf{1 1}$ becomes region $I$. The particle is launched from a coordinate that is randomly selected from those saved when the particle crossed the border between regon $I$ and $I I$ on the previous step. Whenever the particle falls into the hidden region $\mathbf{0}$, it is re-launched at another randomly selected phase space coordinate of the same set. Again, region I is divided into region $I$ and 11accordingto the density after ten thousand damping times, and coordinates are saved for border crossings from region $\mathbf{I}$ to region II during a subsequentten thousand dampingtimes.

The code has been tested in two steps. First, the beam- 


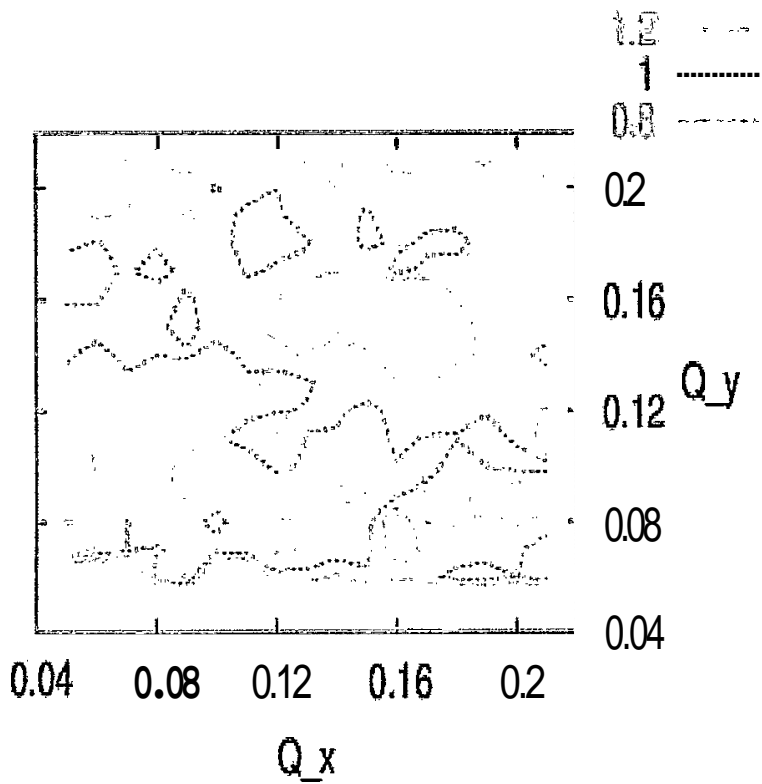

Figure 1: Contourplot of the resulting normalizedluminosity $\mathcal{L} / \mathcal{L}_{0}$ vs. horizontal and vertical electronbeam tune. $\mathcal{L}_{0}$ denotesthe geometric designluminosity accordingto Table 1.

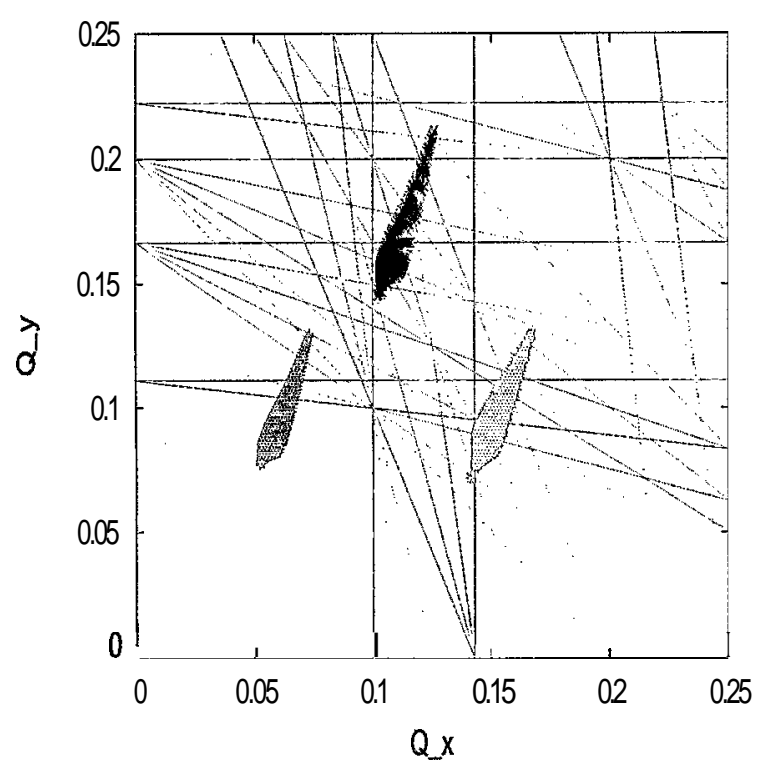

Figure 2: Resonances up to 10th order and necktie diagrams for the three possible eRHIC working points investiated in this study.

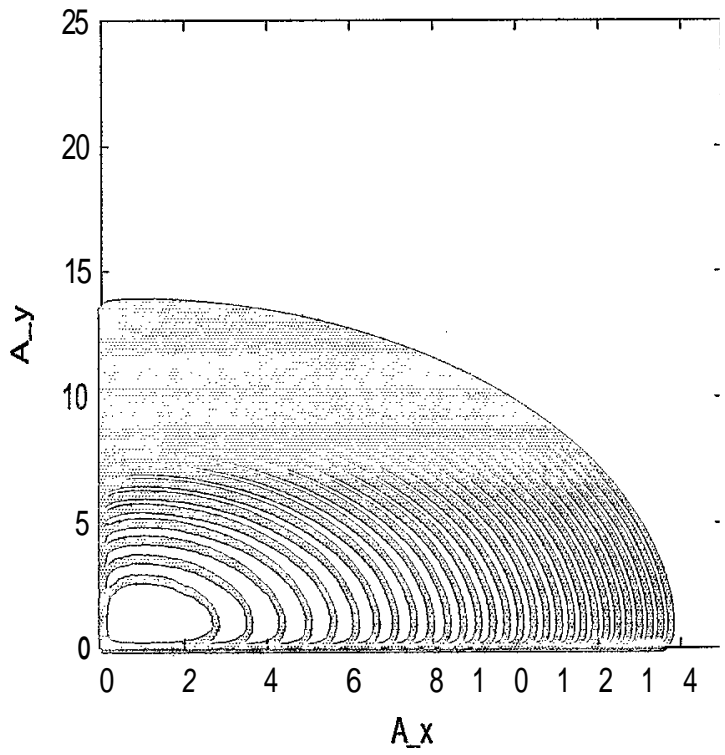

Figure 3: Density contours in the absence of the beambeam interaction, resulting from the simulation. The density decreases by a factor 10 between level lines.

beam interaction was switched off, so the resulting distribution is expected to be just the one corresponding to a regular Gaussian distribution,

$$
\rho\left(A_{x}, A_{y}\right)=A_{x} A_{y} \exp \left(-\frac{A_{x}^{2}+A_{y}^{2}}{2}\right) .
$$

Using the same parameters as given for the examplespresented in Ref. [3], the results agree very well. The distribution resulting fro tracking is depictedin Figure 3 and agrees very well with the analytical expression,Equation 7 .

Three possible eRHIC working points have been identified based on the resulting luminosity performance [4], namely $(.05, .07),(.10, .14)$, and $(.14, .07)$, see Figure 1 . The correspondingnecktie diagrams are depicted in Figure 2 , together with sum resonancesup to 10 thorder.

None of the three working points leads to excessive population of non-Gaussian beam tails. This can be explained by the small beam size ratio of $k=\sigma_{y} / \sigma_{x}=\mathbf{2 . 0}$, which results in a significant drop in the vertical kick when the vertical position of the test particle exceeds the horizontal beam size [5], thus preventing the build-up of a nonGaussian tail in the vertical plane. However, the working point $(.14, .07)$ leads to a significant contribution of electrons at vertical amplitudes up to $20 \sigma_{y}$. While this would not reduce the beam lifetime as long as a minimum vertical aperture of $20 \sigma_{y}$ around the entire machine is guaranteed, this may lead to enhanced background problems from synchrotron radiation emitted by these particles in the interaction region. 


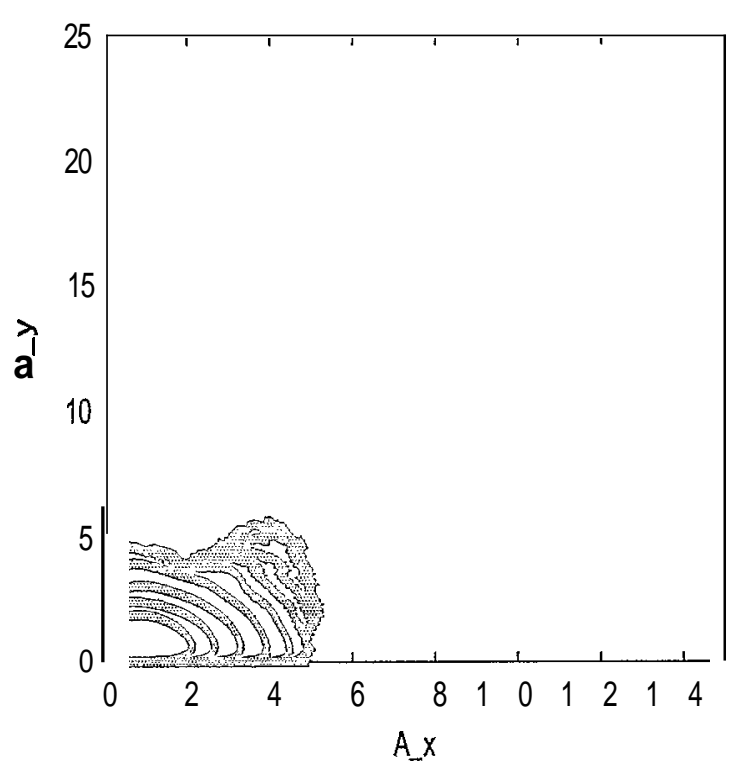

Figure 4: Density contoursfor the working point $(.05, .07)$.

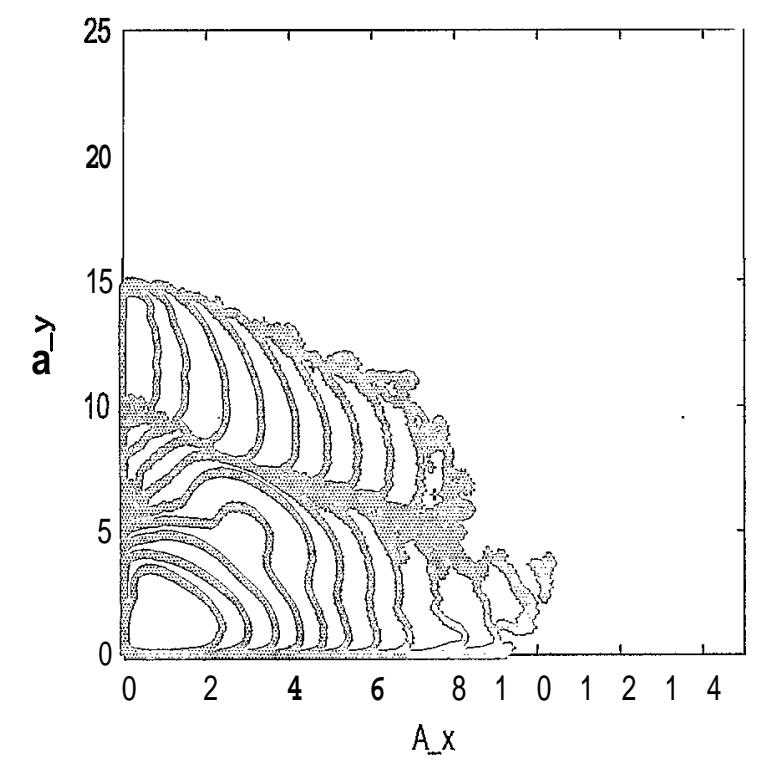

Figure 5: Density contoursfor the working point $(.10, .14)$.

\section{CONCLUSION}

Non-Gaussian transverse beam tails have been studied for three different working points in the proposed eRHIC electron ring, using the method developed by Shatilov [2]. Due to the small ellipticity $\kappa=\sigma_{y} / \sigma_{x}=2.0$ of the eRHIC beams at the interaction point, no excessive population of the vertical electron beam tails occurs. While a minimum aperture of $20 \sigma$ would be sufficient to ensure long beam lifetime, one of the working points studied here leads to

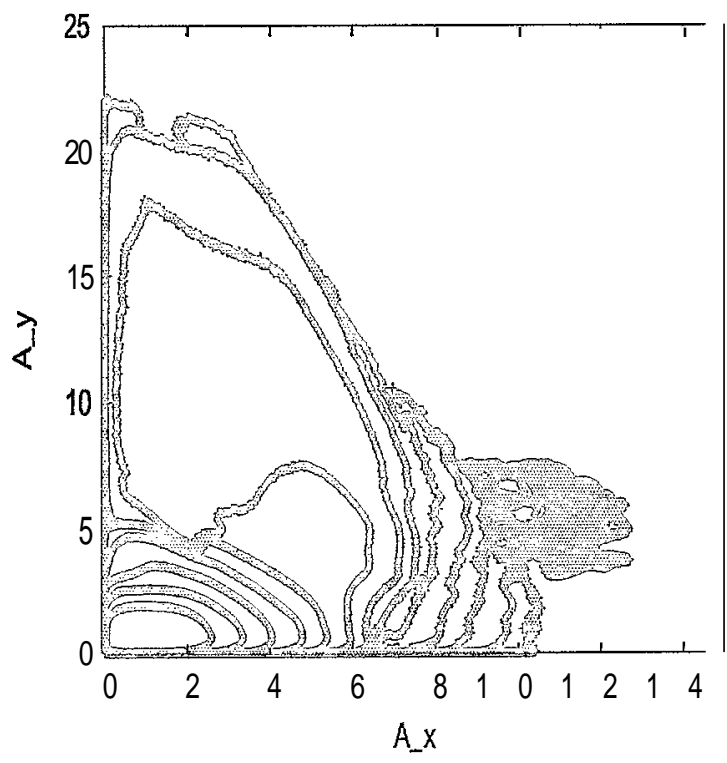

Figure 6: Density contoursfor the working point $(.14, .07)$.

enhanced photon background in the eRHIC detector from electrons at amplitudes as large as $20 \sigma_{y}$.

\section{ACKNOWLEDGMENTS}

The authorwould like to thank Todd Satogata forreading the manuscript.

\section{REFERENCES}

[1] eRHIC Zeroth-Order Design Report, BNL note C-A/AP/142

[2] D. Shatilov, "Beam-beam simulations at large amplitudes and lifetime deternination", Part. Acc. 52, pp. 65-93 (1996)

[3] T. Chen, J. Irwin, and R. Siemann, "Simulation of the beam halo from the beam-beam interaction", Phys. Rev. E 49, pp 2323-2330 (1994)

[4] C. Montag, 'Beam-beam simulations for the eRHIC electron ring", these proceedings

[5] D. N. Shatilov, "Beam-Beam Simulations for the HERA Electron Beam”, DESYHERA 93-12 (1993) 